\title{
RESPONDING TO FINANCIAL PRESSURES. THE EFFECT OF MANAGED CARE ON HOSPITALS' PROVISION OF CHARITY CARE
}

Núria Mas 
The Public-Private Center is a Research Center based at IESE Business School. Its mission is to develop research that analyses the relationships between the private and public sectors primarily in the following areas: regulation and competition, innovation, regional economy and industrial politics and health economics.

Research results are disseminated through publications, conferences and colloquia. These activities are aimed to foster cooperation between the private sector and public administrations, as well as the exchange of ideas and initiatives.

The sponsors of the SP-SP Center are the following:

- Accenture

- Ajuntament de Barcelona

- Caixa Manresa

- Cambra Oficial de Comerç, Indústria i Navegació de Barcelona

- Consell de l'Audiovisual de Catalunya

- Departamento de Economía y Finanzas de la Generalitat de Catalunya

- Departamento de Innovación, Universidades y Empresa de la Generalitat de Catalunya

- Diputació de Barcelona

- Fundació AGBAR

- Garrigues

- Mediapro

- Microsoft

- Sanofi Aventis

- VidaCaixa

The contents of this publication reflect the conclusions and findings of the individual authors, and not the opinions of the Center's sponsors. 


\title{
RESPONDING TO FINANCIAL PRESSURES. THE EFFECT OF MANAGED CARE ON HOSPITALS' PROVISION OF CHARITY CARE
}

\author{
Núria Mas ${ }^{1}$
}

\begin{abstract}
The United States relies on charity to provide the uninsured with medical care, most of which is offered by hospitals that act as providers of last resort and constitute the safety net. Traditionally, these hospitals have been able to finance their provision of unfunded care through a complex system of cross-subsidies. The objective of this paper is to analyze the effects that financial pressures have on the provision of charity care by hospitals. To do so we look at the effect of price pressures and at the cost-controlling mechanisms imposed by managed care. Our hypothesis is that price competition, or other forms of financial pressure, undermines the ability of a hospital to cross-subsidize and challenges their survival. Our results show that managed care has a disproportionately negative effect on the closure of safety net hospitals. Moreover, amongst those that remain open, in areas where managed care penetration increases the most, safety net hospitals react by closing the health services (emergency rooms, obstetrics and alcohol and drug treatments) most commonly used by the uninsured.
\end{abstract}

Keywords: medical, uninsured, hospitals, safety, net.

${ }^{1}$ Professor of Economics, IESE 


\section{RESPONDING TO FINANCIAL PRESSURES. THE EFFECT OF MANAGED CARE ON HOSPITALS' PROVISION OF CHARITY CARE}

\section{Introduction}

In 2007, more than 46 million people in the United States lacked health insurance coverage. ${ }^{2}$ Approximately two-thirds of them lived in families whose income was below 200 percent of the poverty line (Kaiser, 2008). The uninsured are reported to be less likely to receive health care (American College of Physicians-American Society of Internal Medicine, 2000) and more likely to exhibit worst health outcomes (Meara, 1998; Doorslaer et al., 1997; Ettner, 1996).

The United States relies on charity to provide the uninsured with medical care, most of which is offered by hospitals that serve as providers of last resort. They constitute what is called the Safety Net and it consists mainly of teaching hospitals, public hospitals and hospitals located in poor areas. For many years, those hospitals had been able to finance their provision of charity care through a complex system of cross-subsidies from privately-insured paying patients to the uninsured ones. This "hidden tax" has been estimated by the American Hospital Association (1986) to be around 10.5 percent. Hence, a hospital's ability to obtain high revenues plays a crucial role in its facility to provide charity care.

The objective of this paper is to analyze the effects that financial pressures have on the provision of charity care by hospitals. Our first hypothesis is that price competition, or other forms of financial pressure, undermines the ability of a hospital to cross-subsidize. This imposes a large strain on safety net hospitals, challenging their financial sustainability and their survival. Hence, we expect to observe more safety net hospital closures in areas where financial pressures are of greater magnitude.

Our second hypothesis relates to the types of services that the safety net hospitals will provide in areas where financial pressures are more important. The United States system also establishes

\footnotetext{
${ }^{1}$ We are grateful to SP-SP research Centre for research support. We thank David M. Cutler; Bruno Cassiman, and the many participants in the Harvard public finance research seminar and workshop and in the ASHE meetings for comments on a previous draft. We are also grateful to Mireia Raluy and Ona Vilanou for outstanding research assistantship. Financial support from Ministerio de Educación y Ciencia SEJ2006-11833.

2 DeNavas-Walt, C.B. Proctor, and J. Smith, "Income, Poverty, and Health Insurance Coverage in the United States: 2007,” United States Census Bureau; August 2008.
} 
antidumping $^{3}$ rules and requires the hospitals that have emergency rooms to supply emergency indigent care in two situations: a life-threatening health problem or active labor. Given this, we expect that, for the hospitals that remain open, strong financial pressures lead to the closure of precisely the services most commonly used by the uninsured - emergency rooms (Stern et al., 1991), obstetrics (Sloan et al., 1986; Fournier and Campbell, 1997) and alcohol and drug treatment centers (Cousineau, 1997).

For our analysis we will focus on the diffusion of managed care because it is one of the most important changes that the United States healthcare market has experienced in the last decades and it has been identified as a "primary force" affecting hospital revenues (Duke, 1996). Managed care has imposed strong financial pressure and utilization controls on health providers to achieve its cost-containment objective.

Moreover, managed care has played a crucial role in shaping today's healthcare marketplace in the United States. And, today, it completely dominates the United States health care insurance market. It has changed its competition (Baker and Shankarkumar, 1997) and the reimbursement mechanisms for ever. For instance, by initially paying prices about 30 percent below those paid by traditional insurers (Cutler and Barro, 1997), managed care organizations affected the retribution system in the whole marketplace. It contributed to contain doctor wages, not only within the managed care network but also in the entire health care market, increasing competition amongst providers. Hence, even those hospitals that did not belong to the managed care network ended up changing their reimbursement schemes. Understanding the effect of managed care on the provision of charity care by hospitals is a first step in helping us comprehend the role that current financial pressures could have on the health of the uninsured. Our analysis will focus on the period from 1985 to 1995, which corresponds to the diffusion of managed care in the United States.

The impact of the managed care boom has been subjected to close scrutiny in recent years. Most of the literature has concentrated on analyzing the role of managed care in bringing efficiency gains to the health care market or on studying the impact of managed care on the utilization and quality of care for its enrollees. In this respect, Levit et al. (1998) and Melnick and Zwanzinger (1996) point out that managed care is responsible for a large part of the slowdown in expenditure growth in health care. Mas and Seinfeld (2008) show that, by reducing technology adoption, managed care can lead to an important reduction in health care costs, and Luft and Miller (1997) find mixed results for managed care performance on the quality of care for those patients with managed care insurance.

However, most of the research to date has focused on the performance of managed care as compared to other types of health insurance, and very little work has been done to analyze the impact of managed care on the provision of charity care by hospitals. Currie and Fahr (2001) show that, in California, higher rates of managed care penetration lead to an increase in the share of uninsured patients treated by public hospitals at the expense of losing the more profitable Medicaid patients to private hospitals. Richardson (2000) finds a negative impact of managed care on access to care for the poor by observing how the provision of emergency room services and the number of hospitals in poor areas changes with the penetration of managed care.

\footnotetext{
${ }^{3}$ Dumping occurs when a hospital transfers an emergency patient to another or simply refuses any treatment based on the patient's inability to pay.
} 
This paper contributes toward filling the gap in the literature by analyzing the effect that financial pressures and, in particular, managed care penetration have on the provision of uncompensated care by hospitals.

Our results are twofold. First, we find that market pressures established by managed care have a positive effect on the closure of hospitals. As expected from our first hypothesis, this outcome is more important for safety net hospitals since they are now under more financial stress because managed care challenges their ability to keep cross-subsidizing.

Second, our results confirm that, in areas where managed care penetration has increased the most, more of those services generally used by the uninsured have been terminated. This effect is greater for hospitals located in poor neighborhoods and for government hospitals.

Finally, we are also interested in deriving some possible implication that managed care might have on access to care for the uninsured since, by encouraging the closure of safety net hospitals, it can be negatively affected.

The reminder of the paper is organized as follows. Section 2 describes the most relevant characteristics of managed care and the provision of charity care in the United States. Section 3 presents the hypothesis on the effect that financial pressures imposed by managed care might have on the provision of charity care by hospitals. The data is described in Section 4 and the methodology and results are presented in Section 5. Finally, Section 6 concludes.

\section{Managed Care and the Safety Net}

\subsection{Managed Care}

In the past several years, the health care market in the United States has undergone massive changes. The most important has been the shift from traditional insurance to managed care. The percentage of privately-insured Americans that had a health care managed care contract went from 27 percent in 1988 to 93 percent in 2001. Managed care includes a wide variety of health insurance contracts, with health maintenance organizations (HMOs) being the most restrictive ones. Other forms of managed care contracts are the Independent Practice Associations (IPAs), Preferred Provider Organizations (PPOs) and the Point-Of-Service (POS). They differ in the payment to network providers as well as in the copayments faced by the patients when they use services inside and outside the network. For instance, those patients who have an HMO contract are only allowed to visit the network providers and have to pay the full cost if they use someone outside the network. Here, the insurance and provision of health care are fully integrated, doctors are generally paid a salary and they work exclusively for the HMO. In the IPAs, practitioners can contract with as many networks as they wish. Generally, the IPA withholds a share of the fees as a reserve against high costs and this share is given back to the doctors if costs are kept sufficiently low. In PPOs, the insurance company contracts a selected group of providers, who are generally paid on a discounted fee-for-service basis. The insured under this type of contract pay little when they use a physician from the network and more when they use other physicians. Finally, the POS allows its insured to visit providers outside the network but they then face higher copayments. 
Even though there are a wide variety of managed care contracts, they all have some aspects in common: they all involve a controlled form of financing and delivering health care that is based on cost-containment and a controlled use of health care services.

In traditional health insurance plans, a contract can be defined along three dimensions: a premium, a set of covered benefits and a certain copayment that applies to these benefits. In addition to these, managed care plans introduced some additional mechanisms that comprise the selection of providers, the methods used for paying providers and some systems to control service utilization.

Managed care removes free provider choice by establishing a network of pre-approved providers. In general the patient pays nothing (or very little) if she uses the providers in the network but she faces higher costs (they can even be full cost) if she uses a provider that does not belong to the network.

Traditional insurance paid providers on a fee-for-service basis. Managed care uses several reimbursement mechanisms: salaries, capitation and fee-for-service. Nonetheless, even fee-forservice managed care plans pay physicians prices that are below those usually paid by traditional insurance. Cutler and Barro (1997) mention payments that are up to 30 percent below and Gold et al. (1995) also find evidence of a "discounted" fee-for-service paid by managed care.

Managed care uses several methods to control the use of health care services. For instance, it uses primary care physicians as "gatekeepers", requiring their previous referral before the enrollees can consult a specialist. Many plans also limit the number of hospital days and require physicians to follow some established guidelines to treat a certain diagnosis.

\subsection{The Safety Net}

The number of uninsured in the United States has been rising since 1987, jumping from 31.8 million to almost 46 million in 2007. In 2007 about two thirds of the uninsured were poor or near poor (Kaiser, 2008). Moreover, they are less likely to have a regular source of care or get medical care for serious conditions (American College of Physicians, 2000).

Traditionally, the United States has relied on charitable medical care to serve the uninsured. These providers of last resort constitute the Safety Net. The system also establishes antidumping $^{4}$ rules and requires the hospitals that have emergency rooms to supply emergency indigent care in two situations: a life threatening health problem or active labor.

United States spending on uncompensated care ${ }^{5}$ has increased substantially in the past years, growing from 6.1 billion dollars in 1983 to 17.5 billion in 1995 and 24.9 billion in 2003, when its burden represented 5.5\% of hospital total expenses (American Hospital Association). Hospitals have two sources to finance care for the poor: public and private funding. Public financing can be federal, state or local, but most of it comes from Medicare and Medicaid Disproportionate Share (DSH) Adjustments. Medicare DSH was established in 1986 to compensate hospitals for treating a disproportionately large number of Medicaid patients. In 1997 these payments reached 4.8 billion dollars. 93\% of them went to large urban hospitals and

\footnotetext{
${ }^{4}$ Dumping occurs when a hospital transfers an emergency patient to another or simply refuses any treatment based on the patient's inability to pay.

${ }^{5}$ Uncompensated care includes bad debt and charity care provided by the hospital.
} 
65\% went to teaching hospitals. Medicaid DSH was established in 1981 to compensate hospitals with a large share of indigent patients who were not eligible for Medicaid. Private funding includes direct payments from patients as well as a complicated system of cross-subsidies, and hospitals used to raise prices for privately insured patients to cover the costs of providing care to the uninsured (AHA 1991, ${ }^{6}$ Cutler, $1995^{7}$ ).

The distribution of uncompensated care varies greatly among hospital types and location (Table 1): major teaching hospitals represent only $8 \%$ of the market but provide about 30\% of overall uncompensated care. Government hospitals represent a similar situation providing almost 40 percent of the overall uncompensated care, while they account only for $25 \%$ of the American health care market. ${ }^{8}$

The amount of charity care provided by a hospital has two components: demand and supply.

Demand: Distance to the hospital is an important determinant in hospital choice (Burgess and DeFiore, 1994; Currie and Reagan, 1998). Hence, a hospital located in an area with a high proportion of uninsured is more likely to receive uninsured patients who cannot be turned away. Therefore, the demographic composition of the local population is an important determinant in the demand for uncompensated care that the hospital may face.

Supply: The hospital's willingness to provide uncompensated care may differ depending on its ownership. For instance, not-for-profit and government hospitals may be more willing to provide this kind of community service than for-profit ones. Such a mission may be reflected in the services and technologies that the hospital may offer (a substantial number of the poor and uninsured use emergency rooms to receive medical care, and obstetric services are also commonly used by the uninsured) as well as in the location of the hospital (in poor areas as opposed to rich areas). 28.7\% of teaching hospitals, $21.1 \%$ of not-for-profit hospitals and $20.4 \%$ of government hospitals are located in poor areas, while only $15.2 \%$ of for-profit ones are encountered in poor neighborhoods.

Finally, looking at Table 1, we can clearly see that those types of hospitals that provide care to a disproportionate share of the uninsured are public hospitals, teaching hospitals and those located in poor areas. These are the ones that we will identify as safety net hospitals.

\section{Impact of Managed Care on the Hospital's Provision of Charity Care. Hypothesis}

In this section we summarize the effects that the financial pressures imposed by managed care can have on the provision of charity care by hospitals, and we formulate the hypothesis that we will then test empirically.

The first thing that we have to take into account is that different hospitals may have different reasons for providing charity care. For instance, they may care about the indigent population

\footnotetext{
${ }^{6}$ H. Aaron, in a study of the American Hospital Association calculates that the average paying hospital patient subsidizes charity care by paying a "hidden tax" of $10.6 \%$.

${ }^{7}$ Almost a third of uncompensated care is paid by extra charges to the insured patients.

${ }^{8}$ Those hospitals that have a higher burden of charity care also provide care to a higher proportion of Medicaid patients (American Hospital Association).
} 
and extract some utility from providing care to the uninsured, with public and teaching hospitals being more willing to provide this community service than the for-profit ones. This corresponds to what Frank and Salkever (1991) call a "purely altruistic" model. Another reason why hospitals may want to provide free care for the uninsured is because this may increase their reputation in the community or provide them with more donations or better fiscal treatment. ${ }^{9}$ In this case hospitals may compete with the rest of the providers in the market for charity care, and the amount that they provide will also depend on the amount of charity care provided by their rivals. This is what Frank and Salkever (1991) call an "impure altruism" model. Similar reasoning can be applied to quality. Some hospitals may obtain utility directly from providing good quality care to their patients. This again may vary with the hospital ownership. Other hospitals may look at quality as a way to improve their reputation and, thus, to increase their profits. Hence, in our empirical specification we will include a dummy for each relevant hospital type - public hospital $(P)$, teaching hospital $(T)$ and hospitals located in poor areas $(P)$ - to take this into account.

Second, managed care can affect not only the hospitals that belong to its network but also all the hospitals that are in an area where managed care enrollment is substantial. For the hospitals that belong to the network, managed care organizations can have a direct effect since they are able to negotiate better prices and lower quantities of care with the hospitals. This lower reimbursement for the insured reduces the hospital's excess revenues available to finance charity care, and undermines its ability to cross-subsidize uncompensated care. The financial strain that this might imply is stronger for those hospitals that are providing a big share of uncompensated care. Hence we will not only look at the managed care enrollment effect, but we will also interact it with the different hospital types to analyze whether managed care enrollment affects the safety net hospitals more severely.

Hospitals that do not belong to the network observe how they lose some potential patients that have managed care contracts and are forced to go to their network hospitals. This decrease in the number of insured patients challenges their possibility of survival if the hospitals keep providing the same amount of care for the uninsured. Also, the overall market prices and physician practices are affected by managed care (Baker and Shankarkumar, 1997). Hence, the hospitals that do not belong to the network also suffer a reduction in their prices. This decreases hospitals' revenues and makes cross-subsidization of uncompensated care more difficult.

Moreover, managed care organizations may not be interested in including in their network those hospitals that provide a lot of charity care because such hospitals may have to charge higher prices in order to cross-subsidize their uninsured patients. Since a provider that does not belong to the network will not receive any managed care patients, and given the importance of managed care, hospitals may be discouraged from providing uncompensated care in order to be more likely to gain entry into a managed care network.

This is the reason why we will use managed care enrollment measures at the level of the metropolitan area (henceforth, MSA).

Taking this into account, we will test the following hypothesis:

\footnotetext{
${ }^{9}$ Fournier and Campbell (1997) find evidence showing that hospitals in Florida that provide greater amounts of care for the poor are systematically awarded licenses for certificate-of-need approval.
} 
1. Our first hypothesis is that price competition, or other forms of financial pressures, undermines the ability of a hospital to cross-subsidize. This imposes a large strain on safety net hospitals, challenging their financial sustainability and their survival. Hence, we expect to observe more safety net hospital closures in areas where financial pressures are of greater magnitude.

2. Our second hypothesis relates to the types of services that the safety net hospitals will provide in areas where financial pressures are more important. Hospitals that are struggling for survival have more incentives to try to "avoid" non-paying patients. One way of doing so is by closing the set of services most commonly used by the uninsured. The United States system also establishes antidumping rules and requires the hospitals that have emergency rooms to supply emergency indigent care in two situations: a life threatening health problem or active labor. Given this, we expect that, for the hospitals that remain open, strong financial pressures lead to the closure of precisely those services most commonly used by the uninsured. The effects should be particularly severe for the safety net hospitals because they are the ones where the share of charity care patients is the largest. These services include emergency rooms, obstetrics and inpatient and outpatient care for alcohol and drug dependency. Regarding emergency rooms, for many of the United States urban poor, going to the doctor means showing up at a hospital emergency room (Shoor and Hughes, 1993; Stern et al., 1991; Freeman et al., 1990). Moreover, a substantial number of poor uninsured patients use the emergency room for primary care (Freeman and Corey, 1993), and Currie and Reagan (1998) reported that uninsured children are five times more likely than other children to use the emergency room as their regular source of care.

Obstetric units are the other group of services most commonly used by the uninsured. Hospitals are required to accept patients in active labor (Fournier and Campbell, 1997), and about a half of the inpatient admissions for charity care patients correspond to obstetrical deliveries and accident cases (Sloan et al., 1986). Finally, the indigent population is more likely to have alcohol or drug problems (Cousineau, 1997) and, hence, to disproportionately require the use of alcohol and drug treatment centers.

3. Our third hypothesis takes into account the fact that different hospitals may have different reasons for providing charity care, and that safety net hospitals often act as providers of last resort. If this is the case, a safety net hospital that is the only one of its type in the metropolitan area might face many pressures (moral, political, etc) to keep operating, even if the financial environment is very adverse. To test whether this is the case, we will include a dummy variable ONLY that is equal to one if the hospital is the only one of its type (teaching, government, etc.) in the MSA, and zero otherwise.

Finally, one of our objectives is to understand the effect that managed care, through its effect on the provision of charity care by hospitals, could have on access to care for the uninsured. When we look at access to care, the relevant variable to start with is the number of hospitals and services available in the MSA. If one hospital closes its ER and another one opens it, the effect on access to care is less clear. Hence, we will look at the effect that managed care has on the overall number of hospitals and the overall number of ER or obstetric services in the MSA.

\section{Data}

Our goal is to understand the effect that managed care enrollment has had on the number of hospitals as well as on their provision of those health services more used by the uninsured. 
And, in particular, we want to test the hypothesis that those financial pressures have particularly strong effects for safety net hospitals.

Summary statistics of all the following data are presented in Tables $2 \mathrm{a}$ and $2 \mathrm{~b}$.

Hospital data: Information on whether a hospital closed or not and on the types of services it provides (emergency rooms, obstetrics, etc.) comes from the American Hospital Association (AHA).

The AHA also provides information on whether the hospital is public or teaching and it includes its address and zip code. To determine if a hospital belongs to a poor neighborhood, we establish a ranking of the average income per capita in all the zip codes in the United States to find the level corresponding to the thirty-third percentile. Then we compute the average per capita income for the five-mile radius area surrounding the hospital. If it lies below the thirtythird percentile level for the corresponding state, the hospital is considered to be located in a poor neighborhood.

We also include a dummy variable indicating whether the hospital is for profit or not-for-profit and we control for hospital size measured by the number of beds.

Finally, we have also hypothesized the possibility that managed care has a different effect for those hospitals that are the only ones of their type in the MSA, especially if they are the only public hospital in the metropolitan area. We will, then, define a dummy variably ONLY that is equal to one if the hospital if the only one of its type in the MSA.

Market data: Includes the occupancy rate in the MSA, the number of hospitals at the beginning of the period and the average hospital size.

Managed care enrollment: To account for the effect of managed care on the quality of care for the uninsured, we use the share of the MSA population enrolled in HMOs. Unfortunately, enrollment data on other types of managed care contracts is not available. Moreover, HMO enrollment has been the standard measure for managed care enrollment used in the literature - see, for instance, Cutler and McClellan (1996); Baker, (1997); Cutler and Sheiner (1998). The Area Resource File has some information on managed care enrollment at the county level. However, it is problematic because it assigns membership in an HMO to the county where the HMO address is. However, members are usually located in many surrounding areas. In order to avoid this problem, we use data from the Baker estimates in managed care enrollment. Baker constructed estimates of county-level enrollment using data from the Group Health Association of America and he distributed HMO enrollment among the counties of its service area taking into account their population and the distance to the HMO headquarters. Moreover, in order to further lessen any potential problem, our analysis is done at the MSA level.

Finally, there is the possibility that unobservable variables are correlated with both managed care market share and the provision of charity care. For instance, it could be the case that HMO enrollment increased more in the MSA where population also grew more. However, the correlation between the change in HMO penetration and population growth is only 0.018 and hence this should not be a problem. Another possible source of endogeneity is that managed care organizations may prefer those areas where hospitals are already providing little charity care. There is also the possibility that unobservable variables are correlated with both managed care market share and the probability of providing certain services. For instance, patients' preferences for health care, or the health status of the population may be important omitted variables. To correct for these two problems we will use an instrumental variable (IV) approach. 
A possible instrument for the change in HMO penetration that has been widely used in the literature is the average firm size in the corresponding MSA, as first used by Baker (1997). Since large firms are more likely to offer managed care to their employees, areas with large firms are expected to have more managed care. However, large firms are not correlated with the services provided by the hospitals. The average firm size in the MSA is 29.098 workers. The correlation between average MSA firm size and the change in HMO penetration is 0.12.

Demographic characteristics: They include the logarithm of the average family income in the MSA and the percentage of population older than 65 . The demographic information comes from the Current Population Survey (CPS).

Other MSA characteristics: They include the size of the metropolitan area, the percentage of uninsured in the MSA and the percentage of the MSA population with Medicaid and Medicare. The information comes from the Current Population Survey (CPS).

\section{Methods and Results}

The main objective of the paper is to understand the role that financial pressures can play on the provision of charity care by hospitals. However, we would also like to be able to understand the effect that managed care, through its effect on the provision of charity care by hospitals, could have on access to care for the uninsured. For this, we will look at the effect that managed care has had on the overall number of hospitals and services in an MSA, and, in particular, whether this effect is different (i.e., more negative) for the hospitals and services traditionally used by the uninsured.

For each MSA we consider four mutually exclusive hospital types: government hospitals (henceforth, government), teaching-non-government hospitals (henceforth, teaching), nonteaching-non-government hospitals located in poor areas (henceforth, poor) and other hospitals (henceforth, other). Our unit of analysis will be the group of hospitals. Notice that the mutually exclusive categories have been established in such a way to allow us to determine the driving force behind the provision of uncompensated care. Previous literature (Currie and Fahr, 2001) has already singled-out public hospitals from the rest. This is why we included all public hospitals in the first group and the other two categories have been established to be mutually exclusive. The results obtained if we group the hospitals as government, poor-non-government and teaching-non-poor-non-government are robust with the ones presented here.

To illustrate how our data will look, consider a fictitious MSA such as the one depicted below. It contains three public hospitals (P), two government (G), one teaching (T) and five other hospitals $(\mathrm{H})$. There are also two emergency rooms in poor hospitals, two in government hospitals, one in a teaching hospital and three in other hospitals. In this case, for each MSA we would have a maximum of four observations (corresponding to the four quasi-hospital types). For each observation we would have some explanatory variables (such as dummies for the quasi-hospital type: teaching, government, poor and other) and a set of dependent variables (for example, number of hospitals or number of emergency rooms in the quasi-hospital group). 


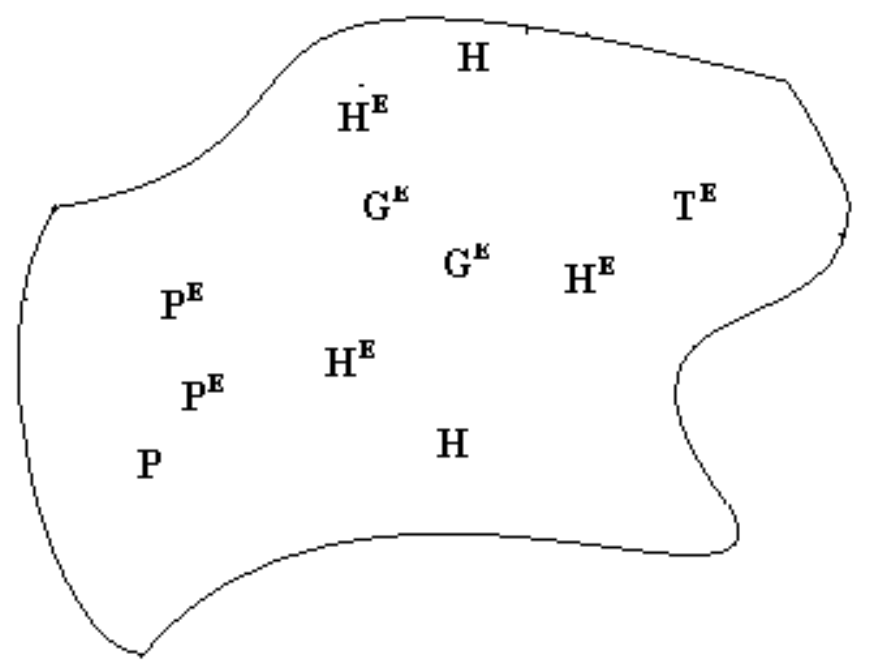

In the fictitious MSA considered here, the data corresponding to the four observations in a particular year would look like this (the first four columns are dummy explanatory variables and the last two correspond to dependent variables):

\begin{tabular}{|l|c|c|c|c|c|c|}
\hline \multicolumn{2}{|c}{ Teaching } & Poor & \multicolumn{1}{c|}{ Government } & Other & \# hospitals & \# ER \\
\hline Obs. 1 & 1 & 0 & 0 & 0 & 1 & 1 \\
\hline Obs. 2 & 0 & 1 & 0 & 0 & 3 & 2 \\
\hline Obs. 3 & 0 & 0 & 1 & 0 & 2 & 2 \\
\hline Obs. 4 & 0 & 0 & 0 & 1 & 5 & 3 \\
\hline
\end{tabular}

Our data contains 894 quasi-hospitals in the 371 United States MSAs, with a maximum of four quasi-hospitals per MSA. There are 122 quasi-hospitals containing only the teaching hospitals in the corresponding MSA, 257 including only the non-teaching government hospitals in the MSA, 171 consisting of non-teaching-non-government hospitals located in poor neighborhoods, and 344 comprising other hospitals. As usual, we have eliminated psychiatric hospitals, hospitals that are a unit of an institution, and rehabilitation hospitals.

Finally, another thing to take into account in our data is the hospital mergers that took place between 1985 and 1995 in the United States. After merging, the two hospitals responded the AHA survey as a single entity. In the AHA, the service questions are of the type "do you have an emergency room?", "do you have an obstetrics unit?" and so on. This means that maybe what we encounter is a reduction on the number of services simply due to the fact that hospitals had merged and are reporting as a single unit. In order to take this into account we have followed a procedure that has already been used in the literature (see, for instance, Mas and Seinfeld, 2008). Imagine the case in which two hospitals $a$ and $b$ merge in year 2 of our sample and that both these hospitals had an emergency room in year one. In our data this would correspond to a reduction in the number of emergency rooms, since in year 1 two hospitals would have reported having one ER and in year 2 only one hospital (the one resulting from the merger) would report having emergency room. In order to avoid this and to be conservative in the effect that managed care could have in the number of hospitals and services provided, we have modified our data in the following way: we have gone backwards and for all the years prior to the merger, we have generated a consolidated hospital that would correspond 
to the merged entity from a and b year 2 backwards. Thus, in year our example, in year 1 , what we would see is only one hospital that would include the services from hospitals $a$ and $b .{ }^{10}$

\subsection{Testing Whether Managed Care Has a More Severe Effect on the Closure of Safety Net Hospitals}

According to our first hypothesis, we expect financial pressures imposed by managed care to disproportionately affect the closure of safety net hospitals, since they have now seen their ability to cross-subsidize ameliorated by managed care.

To test whether this is the case we will define as our dependent variable the change in the number of hospitals of each type (government, teaching, poor and other) from 1985 and 1995. As previously stated, these are the relevant years for the diffusion of managed care in the United States.

We expect this growth to be lower (or even negative) in areas where the rise in managed care penetration $(\triangle H M O)$ is larger and we also expect the impact of managed care to be particularly severe for the safety net hospitals. Hence we will also include the interaction of the change in managed care enrollment with each type of safety net hospital - government (G), teaching $(\mathrm{T})$ and hospitals located in poor areas $(\mathrm{P})$.

As stated in our third hypothesis, a hospital's resistance to closure might be different if it is the only one of its type in the MSA. Hence, we will include also the ONLY dummy and we will interact it with all the hospital types, since the type of pressure that a hospital might receive to remain open might vary with it. For instance, there might be a lot of public pressure to keep the only public hospital in a metropolitan area open.

Finally, we will also control for hospital variables (SIZE) and for the demographic characteristics (DEM) of the MSA.

Our empirical strategy uses the following specification:

$$
\begin{gathered}
\Delta(\text { Number of hospitals } 85-95)_{i}=\phi \Delta H M O_{m s a, i}+\alpha \Delta H M O_{m s a, i} * P_{i}+\beta \Delta H M O_{m s a, i} * T_{i}+\delta \Delta H M O_{m s a, i} * G_{i}+ \\
\theta P_{i}+\omega T_{i}+\rho G_{i}+S I Z E_{l} \gamma+D E M_{m s a} \eta+\lambda O N L Y_{i}+\varphi O N L Y_{i} * P_{i}+\operatorname{vONLY}_{i} * T_{i}+\psi O N L Y_{i} * G_{i}+\varepsilon_{l}
\end{gathered}
$$

Where the subindex $i$ indicates each hospital group in the MSA, and in each MSA there are four groups (the first contains all the government hospitals in the MSA, the second one the teaching-non-government, etc.) $\triangle H M O$ refers to the change in the level of HMO enrollment in the corresponding MSA. Government $(G)$ is a dummy variable equal to one if the hospital group contains the government hospitals in the MSA; teaching $(T)$ is a dummy variable equal to one for the group composed by the MSA hospitals that are teaching-non-government; poor $(P)$ is a dummy variable equal to one if the observation includes the non-teaching-non-government hospitals located in poor areas; $H$ refers to the characteristics of the average hospital in the quasi-hospital; $M$ corresponds to the market characteristics; $D$ to the demographics of the area considered. Finally, our regressions also include states fixed effects. Our benchmark case corresponds to the non-safety net hospitals.

\footnotetext{
${ }^{10}$ Another option would be to simply eliminate the hospitals that have merged from our data and test whether the results are robust. These regressions are available from the authors and the results obtain are robust with the ones presented in the paper.
} 
The results are presented in Table 3. They include the OLS regressions (specification [1]) as well as the corresponding results instrumenting managed care enrollment with firm size. The coefficients in both cases are consistent. To test for robustness we also run the same regressions using logs for the dependent variable and with and without demographic and market control variables. The results are robust.

The first column of Table 3 shows that the increase in managed care enrollment has had a negative but not significant effect on the number of benchmark hospitals. However, this effect becomes significantly negative for government hospitals and hospitals located in poor areas.

The average increase in HMO enrollment between 1985 and 1995 (0.111) implies that the number of hospitals would decrease by 2.6 and 1.8 percent more in poor areas and government hospital groups respectively, than in the benchmark case.

Table 3 also confirms that being the only hospital of a certain type in the MSA has a positive effect on survival, as expected from our hypothesis. However, surprisingly, this plays a positive effect for hospitals located in poor areas, while is not the case for government hospitals.

Overall, this first set of results confirms our first hypothesis of managed care's financial pressures having a negative effect on the number of safety net hospitals. In particular, the impact is especially severe for public hospitals and for those located in poor areas.

\section{a. Testing the effect of managed care on the provision of hospital services most used by the uninsured}

Our second hypothesis states that hospitals facing strong financial pressures imposed by managed care might react by trying to "avoid" non-paying patients. One way of achieving this is by not offering the services most commonly used by the uninsured. As previously established, these are emergency rooms (ER), obstetrics - these two both fall under the antidumping regulation - and alcohol and drug treatments. We expect this reaction to managed care penetration to be stronger for the safety net hospitals, since they are the ones faced with the largest share of charity care patients that they now find harder to cross-subsidize.

To test whether this is the case, we will look at the effect of the increase in managed care enrollment on the following set of dependent variables (Y): the change in the number of emergency rooms, the change in the number of hospitals offering obstetric services and the change in the number of hospitals that offer alcohol and drug treatment centers.

Our empirical strategy uses the following expression:

$$
\begin{gathered}
\Delta(\text { Number of hospitals } 85-95)_{i}=\phi \Delta H M O_{m s a, i}+\alpha \Delta H M O_{m s a, i} * P_{i}+\beta \Delta H M O_{m s a, i} * T_{i}+\delta \Delta H M O_{m s a, i} * G_{i}+ \\
\theta P_{i}+\omega T_{i}+\rho G_{i}+S I Z E_{l} \gamma+D E M_{m s a} \eta+\lambda O N L Y_{i}+\varphi O N L Y_{i} * P_{i}+\operatorname{VONLY}_{i} * T_{i}+\psi O N L Y_{i} * G_{i}+\varepsilon_{l}
\end{gathered}
$$

The explanatory variables are the same as in the previous test and they are included for the same reasons as the ones established in section 4.2.

Results are presented in Table 4. They show that a rise in HMO enrollment has a more negative effect on the number of hospitals that offer ER, obstetric units and inpatient centers for alcohol and drug treatment, for government hospitals and hospitals located in poor areas. Interestingly, this is not the case for outpatient alcohol and drug treatment centers.

The average increase in HMO enrollment between 1985 and 1995 implies that the number of hospitals with ER services would fall by 7.4 and 2.8 percent more in government hospitals and 
in those located in poor areas, than in the baseline ones. The number of hospitals that offer obstetric services would decrease by 5.8 percent more in poor area hospitals than in the baseline case and the number of inpatient alcohol and drug treatment centers would diminish by 5.8 and 1.9 percent more in poor hospitals and in government hospitals, respectively, than in the baseline ones.

The effect of managed care on the number of these services provided by teaching hospitals is not significantly different from zero. Finally, we observe that the change in HMO enrollment does not have an effect on the number of alcohol and drug treatment centers provided on an outpatient basis. In fact, during this period, 46 percent of the hospitals that closed their inpatient center for patients with alcohol and drug problems already had an outpatient center, and the 12 percent of the hospitals that did not have one opened new outpatient centers for alcohol and drug treatment (AHA Annual Survey). Hence, there seems to be a tendency for hospitals to substitute this type of inpatient care with outpatient service, especially in areas where managed care pressures are important. This tendency does not significantly differ whether it is a teaching, government or poor hospital group. To test whether this is the case, we created a variable that accounts for the overall number of alcohol and drug treatment centers in a group of hospitals regardless of their inpatient or outpatient status. Results using this dependent variable are reported in columns [9] and [10] of Table 4, and show that managed care did not differently affect different hospital types regarding the provision of the overall alcohol and drug inpatient and outpatient centers.

Another interesting set of variables is the one that accounts for the fact that hospitals that are the only ones of their type in an MSA may react differently as they face different market pressures. On the other hand, certain types of hospitals, mainly government ones, may be forced to remain open if they are the only one in the MSA. As expected according to our third hypothesis, the ONLY dummy is positive. It is significantly different from zero for the change in the number of hospitals in the market, obstetrics and outpatient centers for alcohol and drug treatment. The interaction of this dummy with government hospital is positive and significant for the change in ER, obstetrics and alcohol and drug treatment centers.

However, all these results could only be reflecting the fact that safety net hospitals are less efficient to start with, and they have been forced to shut down or to terminate their services with the introduction of managed care. To see if managed care has a differential effect for the services most commonly used by the uninsured, reflecting that it is making it more difficult for hospitals to cross-subsidize charity care, we will also look at the effect of an increase in the HMO enrollment for other types of hospital services that are not disproportionately used by charity care patients. Results are presented in Table 5.

None of the coefficients corresponding to the interaction of the change in HMO enrollment and safety net hospital types is significant. However, given that the AHA survey only asks whether the hospital provides the service, if a hospital closes some of its units but is still offering the service no change will be shown in the data. Hence, our findings may show that managed care has no significantly different effect on poor and teaching hospitals from the control group, when, in fact, the number of units of service available has been reduced. To rule out this possibility, in the last three columns of Table 5 we take advantage of the fact that the AHA also asks about the number of beds assigned to cardiac intensive care, burn care and medical/surgical intensive care. In none of the cases has managed care had a differential impact on poor, government and teaching areas regarding the number of beds assigned to a particular 
service. Here, the only dummy remains generally positive. When interacted with government markets it is only significant and positive for the change in dental services.

Our results from Table 4 and Table 5 confirm that managed care has had a disproportionate effect on the number of services often used by the uninsured, even more so for the safety net hospitals.

\section{Conclusions}

Traditionally, safety net hospitals have been able to finance part of the charity care they provide through a complex system of cross-subsidies. A rise in price competition and a reduction of their revenues from insured patients might threaten this delicate equilibrium.

To evaluate the importance of financial pressures on the provision of charity care by hospitals, we look at the impact of managed care.

The managed care boom has been one of the most important changes in the United States healthcare market and it has contributed to decreasing the reimbursement to hospitals and doctors in the whole marketplace.

The results of this paper show that managed care penetration, by rising price competition and reducing hospital revenues, has exacerbated the closure of safety net hospitals. Moreover, the ones that remain open disproportionately terminate the provision of those services generally used by the uninsured in areas where managed care enrollment is higher. This is especially the case for government hospitals.

These results have important implications for uninsured patients' access to care. A reduction of the number of safety net hospitals and their higher termination of the services traditionally used by the uninsured implies that the average patient in the area has to travel longer distances to obtain medical care. Numerous works in health economics literature find a negative elasticity of distance on access to care (see, for instance, Currie and Reagan, 1998, or Goodman et al., 1997). Further research should focus on the ultimate impact that managed care has had on access to care and quality of care for the uninsured. 


\section{References}

American College of Physicians-American Society of Internal Medicine (2000), "No Health Insurance? It's enough to Make you Sick," Philadelphia, American College of PhysiciansAmerican Society of Internal Medicine.

American Hospital Association (1986), "Cost and Compassion: Recommendations for Avoiding a Crisis in Care for the Medically Indigent," Chicago.

Baker, L. (1997), "The effect of HMOs on fee-for-service health care expenditures. Evidence from Medicare," Journal of Health Economics, 16.

Baker, L. (1999), "Association of managed care market share and health expenditure for fee-forservice Medicare patients," Journal of the American Medical Association, pp. 432-437.

Baker, L. and S. Shankarkumar (1997), "Managed Care and Health Care Expenditures: Evidence from Medicare, 1990-1994,” NBER Working Paper 6187.

Burguess J., D. A. DeFiore (1994), "The effect of distance to VA facilities on the choice and level of utilization of VA outpatient services," Social Science and Medicine, July.

Cousineau, M. (1997), "Health Status of and Access to Health Services by Residents of Urban Encampments in Los Angeles," Journal of Health Care for the Poor and Underserved, February.

Currie, J. and J. Fahr (2001), "Hospitals, Managed Care and the Charity Caseload in California," NBER Working Paper 8621.

Currie, J. and P. Reagan (1998), "Distance to hospital and children's access to care: is being closer better, and for whom?,” NBER Working Paper 6836.

Cutler, D. and J. Barro (1997), "Consolidation in the Medical care Marketplace: a Case Study for Massachusetts,” NBER Working Paper 5957.

Cutler, D. and M. McClellan (1996), “The Determinants of Technological Chance in Heart Attack Treatments," NBER Working Paper 5751.

Cutler, D. M. and L. Sheiner (1998), "Managed care and the growth of medical expenditures," NBER Working Paper 6140.

Doorslaer, E. et al. (1997), "Income-Related Inequalities in Health: some International Comparisons," Journal of Health Economics, vol. 16, pp. 93-112.

Duke, K. (1996), “Hospitals in a changing healthcare system,” Health Affairs, 15(2), pp. 49-61.

Ettner, S. (1996), “New Evidence on the Relationship between Income and Health,” Journal of Health Economics, (15), pp. 67-85.

Frank, R. and R. Salkever (1991), "The Supply of Charity Services by Not-For-Profit Hospitals: Motives and Market Structure," RAND Journal of Economics, 22(3), pp. 430-445.

Freeman, H., L. Aiken, R. Blendon, and C. Corey (1990), "Uninsured working-Age Adults: Characteristics and Consequences," Health Services Research, February. 
Freeman, E. and C. Corey (1993), "Insurance Status and Access to Health Services among Poor Persons," Health Services Research, 24(6).

Fournier and Campbell (1997), “Indigent Care as Quid Pro Quo in Hospital Regulation,” The Review of Economics and Statistics, November.

Gold, M.R. et al. (1995), "A National survey of the arrangements Managed Care Plans Make with Physicians," New England Journal of Medicine; 333 (25), pp. 1678-1683.

Kaiser (2008), "The Uninsured: A Primer," The Kaiser Commission on Medicaid and the Uninsured, October.

Levit, K., H. Lazenby, and B. Braden (1998), "National health Spending Trends," Health Affairs, 17.

Luft, S. and R. Miller (1997), "Does Managed Care Lead to Better or Worse Quality of Care?," Health Affairs, September-October.

Mas, N. and J. Seinfeld (2008), "Is Managed care restraining the adoption of technology by hospitals?," Journal of Health Economics, 27, pp. 1026-1045.

Meara, E. (1998), “Why is Socioeconomic Status Related to Health?," mimeo.

Melnick, G. and J. Zwanziger (1995), "State Health Care Expenditures under Competition and Regulation, 1980 through 1991," American Journal of Public Health, 85(10).

Richardson, E. (1999), "Managed Care and Access to Care by the Poor," mimeo.

Shoor, R. and C. Hughes (1993), "Cities Struggle to Pay for Health Care," Business and Health, 1993.

Sloan, F., M. Morrisey, and J. Valvona (1986), "Hospital Care for the 'Self Pay' Patient," Journal of Health Politics, Policy and Law, vol. 13, pp. 83-102.

Stern, R., J. Weissman, and A. Epstein (1991), "The Emergency Department as a Pathway to Admission for Poor and High-Cost Patients," JAMA, 1991. 


\section{Table 1}

Uncompensated Care by Hospital Type

\begin{tabular}{|c|c|c|c|c|c|c|}
\hline \multirow[b]{2}{*}{ Hospital type } & \multicolumn{2}{|c|}{ UC Share } & \multicolumn{2}{|c|}{ Mrkt Share } & \multicolumn{2}{|c|}{ UC/Expenses } \\
\hline & 1985 & 1995 & 1985 & 1995 & 1985 & 1995 \\
\hline \multicolumn{7}{|l|}{ Ownership } \\
\hline Non-For-Profit & $55.60 \%$ & $55.80 \%$ & $58.06 \%$ & $59.64 \%$ & $4.10 \%$ & $5.00 \%$ \\
\hline For-Profit & $4.10 \%$ & $5.30 \%$ & $15.10 \%$ & $15.35 \%$ & $3.10 \%$ & $4.20 \%$ \\
\hline Government & $40.30 \%$ & $38.90 \%$ & $26.84 \%$ & $25.01 \%$ & $11.12 \%$ & $12.27 \%$ \\
\hline \multicolumn{7}{|l|}{ Teaching Status } \\
\hline Major public teaching & $25.20 \%$ & $26.50 \%$ & $1.46 \%$ & $1.52 \%$ & $8.20 \%$ & $9.10 \%$ \\
\hline Major private teaching & $4.60 \%$ & $12.40 \%$ & $5.28 \%$ & $4.88 \%$ & $13.60 \%$ & $14.50 \%$ \\
\hline
\end{tabular}

Source: American Hospital Association.

UC refers to Uncompensated Care, that includes charity care and bad debt.

$U C$ share refers to the percentage of total uncompensated care provided by each hospital type.

MKT share refers to percentage of total hospital beds provided by each hospital group.

Table 2.a

Summany Statistics. Dependent Variables

\begin{tabular}{|c|c|c|c|c|}
\hline \multirow[b]{2}{*}{ Variable Name } & \multicolumn{2}{|c|}{ Variable in 1985} & \multicolumn{2}{|c|}{ Variable in 95/variable in 85} \\
\hline & Mean & $\overline{\text { Std. Deviation }}$ & Mean & Std. Deviation \\
\hline \multicolumn{5}{|l|}{ \# Hospitals } \\
\hline Poor & 3.082 & 4.793 & 0.722 & 0.366 \\
\hline Teaching & 3.025 & 4.175 & 0.874 & 0.238 \\
\hline Government & 2.564 & 2.685 & 0.822 & 0.307 \\
\hline Other & 6.706 & 10.068 & 0.832 & 0.243 \\
\hline \multicolumn{5}{|c|}{ \# Emergency Rooms } \\
\hline Poor & 2.146 & 2.846 & 0.658 & 0.439 \\
\hline Teaching & 2.836 & 3.784 & 0.840 & 0.353 \\
\hline Government & 1.416 & 1.857 & 0.722 & 0.466 \\
\hline Other & 4.738 & 6.570 & 0.798 & 0.348 \\
\hline \multicolumn{5}{|l|}{ \# Obstetrics } \\
\hline Poor & 1.392 & 1.800 & 0.714 & 0.515 \\
\hline Teaching & 2.459 & 3.407 & 0.833 & 0.310 \\
\hline Government & 1.058 & 1.556 & 0.708 & 0.453 \\
\hline Other & 3.480 & 4.798 & 0.853 & 0.441 \\
\hline \multicolumn{5}{|c|}{ \# Inpatient Alcohol \& Drug Care Units } \\
\hline Poor & 0.930 & 1.349 & 0.450 & 0.623 \\
\hline Teaching & 1.246 & 2.191 & 0.565 & 0.490 \\
\hline Government & 0.537 & 0.824 & 0.580 & 0.658 \\
\hline Other & 2.241 & 3.420 & 0.663 & 0.653 \\
\hline \multicolumn{5}{|c|}{ \# Outpatient Alcohol \& Drug Care Units } \\
\hline Poor & 0.649 & 1.076 & 0.561 & 0.646 \\
\hline Teaching & 1.115 & 2.272 & 0.914 & 0.620 \\
\hline Government & 0.339 & 0.774 & 0.450 & 0.573 \\
\hline Other & 1.404 & 2.348 & 0.844 & 0.691 \\
\hline \multicolumn{5}{|c|}{ \# Any Alcohol \& Drug Care Units } \\
\hline Poor & 1.041 & 1.420 & 0.576 & 0.655 \\
\hline Teaching & 1.533 & 2.679 & 0.858 & 0.513 \\
\hline Government & 0.661 & 1.089 & 0.607 & 0.655 \\
\hline Other & 2.439 & 3.830 & 0.791 & 0.688 \\
\hline
\end{tabular}


Table 2.b

Summary Statistics. Dependent Variables. Control Group of Services

\begin{tabular}{|c|c|c|c|c|}
\hline \multirow[b]{2}{*}{ Variable Name } & \multicolumn{2}{|c|}{ Variable in 1985} & \multicolumn{2}{|c|}{ Variable in 95/ Variable in 85} \\
\hline & Mean & Std. Deviation & Mean & Std. Deviation \\
\hline \multicolumn{5}{|c|}{ \# Dental Care Units } \\
\hline Poor & 1.380 & 1.561 & 0.277 & 0.413 \\
\hline Teaching & 2.533 & 3.733 & 0.561 & 0.430 \\
\hline Government & 1.374 & 1.728 & 0.367 & 0.454 \\
\hline Other & 2.959 & 4.186 & 0.352 & 0.473 \\
\hline \multicolumn{5}{|c|}{ \# Cardiac Intensive Care Units } \\
\hline Poor & 2.041 & 2.833 & 0.465 & 0.429 \\
\hline Teaching & 2.828 & 3.858 & 0.795 & 0.320 \\
\hline Government & 1.074 & 1.653 & 0.526 & 0.544 \\
\hline Other & 4.350 & 6.239 & 0.646 & 0.413 \\
\hline \multicolumn{5}{|l|}{ \# Burn Care Units } \\
\hline Poor & 0.240 & 0.442 & 0.150 & 0.362 \\
\hline Teaching & 1.221 & 1.189 & 0.573 & 0.467 \\
\hline Government & 0.097 & 0.346 & 0.357 & 0.451 \\
\hline Other & 0.416 & 0.785 & 0.239 & 0.448 \\
\hline \multicolumn{5}{|c|}{ \# Medical/Surgical Intensive Care (MSIC) } \\
\hline Poor & 2.163 & 3.133 & 0.623 & 0.442 \\
\hline Teaching & 2.844 & 3.783 & 0.802 & 0.292 \\
\hline Government & 1.218 & 1.765 & 0.729 & 0.465 \\
\hline Other & 4.683 & 6.594 & 0.759 & 0.333 \\
\hline \multicolumn{5}{|l|}{ \# Cardiac IC Beds } \\
\hline Poor & 7.667 & 12.318 & 0.784 & 0.819 \\
\hline Teaching & 25.934 & 40.102 & 1.156 & 1.287 \\
\hline Government & 3.210 & 8.013 & 0.764 & 0.816 \\
\hline Other & 16.785 & 29.365 & 1.076 & 1.031 \\
\hline \multicolumn{5}{|l|}{ \# Burn Care Beds } \\
\hline Poor & 0.626 & 3.001 & 0.852 & 0.962 \\
\hline Teaching & 7.361 & 9.023 & 0.834 & 0.519 \\
\hline Government & 0.296 & 1.624 & 0.699 & 0.709 \\
\hline Other & 0.933 & 3.680 & 0.754 & 0.906 \\
\hline \multicolumn{5}{|l|}{ \# MSIC Beds } \\
\hline Poor & 23.772 & 35.408 & 0.768 & 0.730 \\
\hline Teaching & 64.377 & 87.167 & 1.095 & 0.600 \\
\hline Government & 11.202 & 17.774 & 0.923 & 0.727 \\
\hline Other & 52.125 & 80.200 & 0.959 & 0.687 \\
\hline
\end{tabular}




\section{Table 3}

Managed care effects on the number of hospitals

\begin{tabular}{|c|c|c|}
\hline & OLS & IV \\
\hline \multirow[t]{2}{*}{ HMO change*poor } & $-0.237^{* *}$ & $-0.265^{\star \star}$ \\
\hline & [0.122] & {$[0.16]$} \\
\hline \multirow[t]{2}{*}{ HMO change*teaching } & $-0,116$ & $-0,124$ \\
\hline & {$[0.120]$} & {$[0.121]$} \\
\hline \multirow[t]{2}{*}{ HMO change * gov } & $-0.163^{*}$ & $-0.174^{*}$ \\
\hline & {$[0.098]$} & {$[0.090]$} \\
\hline \multirow[t]{2}{*}{ Poor } & $-0,052$ & $-0.066^{*}$ \\
\hline & {$[0.036]$} & {$[0.046]$} \\
\hline \multirow[t]{2}{*}{ Teaching } & $-0,054$ & $-0,061$ \\
\hline & {$[0.044]$} & {$[0.046]$} \\
\hline \multirow[t]{2}{*}{ Government } & $-0,004$ & $-0,013$ \\
\hline & {$[0.028]$} & {$[0.029]$} \\
\hline \multirow[t]{2}{*}{ HMO Change } & $-0,020$ & $-0,040$ \\
\hline & {$[0.070]$} & {$[0.070]$} \\
\hline \multirow[t]{2}{*}{ Only hospital } & $0.131^{\star \star}$ & $0.125^{\star \star}$ \\
\hline & {$[0.022]$} & {$[0.023]$} \\
\hline \multirow[t]{2}{*}{ only hospitalpoor } & $0.070^{*}$ & $0.081^{* *}$ \\
\hline & {$[0.036]$} & {$[0.038]$} \\
\hline \multirow[t]{2}{*}{ only hospital`Teaching } & 0,060 & 0,064 \\
\hline & {$[0.039]$} & {$[0.040]$} \\
\hline \multirow[t]{2}{*}{ Only hospital ${ }^{\star}$ gov } & 0,009 & 0,018 \\
\hline & {$[0.028]$} & {$[0.030]$} \\
\hline Demographic Characteristics & yes & yes \\
\hline Hospital Characteristics & yes & yes \\
\hline Market Characteristics & yes & yes \\
\hline $\mathbf{N}$ & 894 & 894 \\
\hline R2 & 0.173 & 0.174 \\
\hline
\end{tabular}

Robust standard errors appear in brackets.

All regressions include 51 state dummy variables and 7 MSA size dummy variables.

* Statistically significantly different from zero at the 10 percent level.

${ }^{*}$ Statistically significantly different from zero at the 5 percent level. 


\section{Table 4}

Managed Care Effects on the Services Provided

\begin{tabular}{|c|c|c|c|c|c|c|c|c|c|c|}
\hline & \multicolumn{2}{|c|}{ ER } & \multicolumn{2}{|c|}{ Obstetrics } & \multicolumn{2}{|c|}{ Inp. alcoh\&drug } & \multicolumn{2}{|c|}{ Outp. alcoh\&drug } & \multicolumn{2}{|c|}{ Any alcoh\&drug } \\
\hline & $\begin{array}{c}\text { OLS } \\
\text { [1] }\end{array}$ & $\begin{array}{l}\text { IV } \\
\text { [2] }\end{array}$ & $\begin{array}{c}\text { OLS } \\
\text { [3] }\end{array}$ & $\begin{array}{l}\text { IV } \\
\text { [4] }\end{array}$ & $\begin{array}{c}\text { OLS } \\
\text { [5] }\end{array}$ & $\begin{array}{l}\text { IV } \\
\text { [6] }\end{array}$ & $\begin{array}{c}\text { OLS } \\
7]\end{array}$ & $\begin{array}{l}\text { IV } \\
{[8]}\end{array}$ & $\begin{array}{c}\text { OLS } \\
\text { [9] }\end{array}$ & $\begin{array}{c}\text { IV } \\
{[10]}\end{array}$ \\
\hline \multirow{2}{*}{ HMO change*poor } & $-0.258^{*}$ & $-0.311^{* *}$ & $-0.527^{\star}$ & $-0.438^{*}$ & $-0.526^{* *}$ & $-0.534^{*}$ & 0.688 & 0.417 & -0.490 & -0.528 \\
\hline & {$[0.143]$} & {$[0.215]$} & {$[0.293]$} & {$[0.249]$} & {$[0.270]$} & {$[0.278]$} & [0.679] & {$[0.716]$} & [0.547] & [0.567] \\
\hline \multirow[t]{2}{*}{ HMO change ${ }^{\star}$ teaching } & -0.189 & -0.195 & 0.094 & 0.113 & -0.461 & -0.369 & 0.198 & 0.115 & -0.381 & -0.293 \\
\hline & {$[0.194]$} & {$[0.198]$} & {$[0.240]$} & {$[0.254]$} & {$[0.487]$} & {$[0.505]$} & [0.626] & {$[0.628]$} & {$[0.543]$} & [0.564] \\
\hline \multirow{2}{*}{ HMO change * gov } & $-0.668^{* *}$ & $-0.624^{* \star}$ & -0.245 & -0.259 & $-0.175^{* *}$ & $-0.184^{\star \star}$ & 0.028 & -0.455 & -0.273 & -0.287 \\
\hline & {$[0.289]$} & {$[0.292]$} & [0.353] & {$[0.367]$} & {$[0.075]$} & {$[0.078]$} & [0.671] & {$[0.627]$} & [0.535] & [0.551] \\
\hline \multirow[t]{2}{*}{ Poor } & -0.075 & $-0.105^{\star}$ & -0.081 & -0.117 & -0.119 & -0.104 & -0.132 & -0.071 & -0.044 & -0.016 \\
\hline & {$[0.058]$} & {$[0.063]$} & {$[0.079]$} & {$[0.085]$} & {$[0.125]$} & [0.133] & {$[0.145]$} & {$[0.146]$} & {$[0.128]$} & [0.134] \\
\hline \multirow[t]{2}{*}{ Teaching } & 0.059 & 0.034 & $-0.285^{\star *}$ & $-0.289^{\star \star}$ & -0.113 & -0.096 & 0.209 & 0.232 & 0.192 & 0.213 \\
\hline & {$[0.086]$} & {$[0.087]$} & {$[0.086]$} & {$[0.093]$} & [0.148] & {$[0.151]$} & [0.226] & {$[0.218]$} & {$[0.157]$} & [0.160] \\
\hline \multirow{2}{*}{ Government } & 0.082 & 0.076 & $-0.123^{*}$ & $-0.128^{\star}$ & -0.043 & -0.018 & -0.147 & -0.103 & -0.054 & -0.023 \\
\hline & {$[0.059]$} & {$[0.060]$} & {$[0.067]$} & {$[0.070]$} & [0.110] & {$[0.116]$} & [0.130] & {$[0.137]$} & {$[0.107]$} & [0.111] \\
\hline \multirow[t]{2}{*}{ HMO Change } & 0.005 & 0.063 & -0.094 & -0.050 & $-0.415^{*}$ & -0.470 & 0.022 & 0.104 & 0.455 & 0.516 \\
\hline & {$[0.118]$} & {$[0.120]$} & {$[0.184]$} & {$[0.191]$} & [0.251] & {$[0.373]$} & [0.390] & {$[0.387]$} & {$[0.365]$} & [0.377] \\
\hline \multirow[t]{2}{*}{ Only hospital } & 0.024 & 0.021 & $0.183^{\star *}$ & $0.210^{* *}$ & 0.103 & 0.090 & $0.358^{\star *}$ & $0.374^{\star \star}$ & 0.035 & 0.028 \\
\hline & [0.069] & {$[0.074]$} & {$[0.087]$} & {$[0.096]$} & {$[0.200]$} & {$[0.204]$} & {$[0.159]$} & {$[0.153]$} & {$[0.198]$} & [0.198] \\
\hline \multirow[t]{2}{*}{ Only hospital*poor } & 0.040 & 0.063 & 0.162 & 0.201 & -0.377 & -0.324 & $-0.518^{\star *}$ & $-0.526^{*}$ & -0.345 & -0.281 \\
\hline & {$[0.107]$} & {$[0.114]$} & {$[0.131]$} & {$[0.141]$} & [0.279] & {$[0.290]$} & [0.265] & {$[0.268]$} & {$[0.275]$} & [0.286] \\
\hline \multirow[t]{2}{*}{ Only hospital*Teaching } & 0.043 & 0.043 & $0.334^{\star *}$ & $0.349^{\star \star}$ & -0.287 & -0.363 & $-0.128^{\star \star}$ & -0.130 & $-0.546^{* *}$ & -0.608 \\
\hline & {$[0.097]$} & {$[0.103]$} & {$[0.108]$} & {$[0.115]$} & [0.255] & {$[0.261]$} & {$[0.284]$} & {$[0.289]$} & {$[0.258]$} & [0.261] \\
\hline \multirow[t]{2}{*}{ Only hospital*gov } & $0.125^{*}$ & $0.129^{\star}$ & $0.090^{\star *}$ & 0.156 & $0.305^{*}$ & $0.285^{\star}$ & -0.493 & $-0.494^{\star}$ & -0.234 & -0.214 \\
\hline & {$[0.073]$} & {$[0.074]$} & [0.041] & {$[0.128]$} & [0.181] & {$[0.144]$} & [0.275] & {$[0.257]$} & {$[0.235]$} & [0.233] \\
\hline Demographic Characteristics & yes & yes & yes & yes & yes & yes & yes & yes & yes & yes \\
\hline Hospital Characteristics & yes & yes & yes & yes & yes & yes & yes & yes & yes & yes \\
\hline Market Characteristics & yes & yes & yes & yes & yes & yes & yes & yes & yes & yes \\
\hline $\mathbf{N}$ & 894 & 894 & 894 & 894 & 894 & 894 & 894 & 894 & 894 & 894 \\
\hline R2 & 0.154 & 0.163 & 0.180 & 0.202 & 0.268 & 0.286 & 0.289 & 0.331 & 0.237 & 0.265 \\
\hline
\end{tabular}

Robust standard errors appear in brackets. All regressions include 51 state dummy variables and 7 MSA size dummy variables.

* Statistically significantly different from zero at the 10 percent level.

** Statistically significantly different from zero at the 5 percent level.

20 - IESE Business School-University of Navarra 


\section{Table 5}

Managed Care Effects on Number of Services in the Market. Control Group

\begin{tabular}{|c|c|c|c|c|c|c|c|c|c|c|c|c|c|c|}
\hline & \multicolumn{2}{|c|}{ Dental } & \multicolumn{2}{|c|}{ Cardiac IC } & \multicolumn{2}{|c|}{ Burn Care } & \multicolumn{2}{|c|}{ Medical/Surgical IC } & \multicolumn{2}{|c|}{ Cardiac IC Beds } & \multicolumn{2}{|c|}{ Burn Beds 9} & \multicolumn{2}{|c|}{ Med/Surg IC Beds } \\
\hline & $\begin{array}{l}\text { OLS } \\
\text { [1] }\end{array}$ & $\begin{array}{l}\text { IV } \\
{[2]}\end{array}$ & $\begin{array}{l}\text { OLS } \\
\text { [3] }\end{array}$ & $\begin{array}{c}\text { IV } \\
{[4]}\end{array}$ & $\begin{array}{l}\text { OLS } \\
{[5]}\end{array}$ & $\begin{array}{l}\text { IV } \\
{[6]}\end{array}$ & $\begin{array}{l}\text { OLS } \\
\text { [7] }\end{array}$ & $\begin{array}{l}\text { IV } \\
{[8]}\end{array}$ & $\begin{array}{l}\text { OLS } \\
\text { [9] }\end{array}$ & $\begin{array}{r}\text { IV } \\
{[10]}\end{array}$ & $\begin{array}{l}\text { OLS } \\
\text { [11] }\end{array}$ & $\begin{array}{r}\text { IV } \\
\text { [12] }\end{array}$ & $\begin{array}{c}\text { OLS } \\
\text { [13] }\end{array}$ & $\begin{array}{r}\text { IV } \\
{[14]}\end{array}$ \\
\hline HMO change*poor & $\begin{array}{l}-0.379 \\
{[0.379]}\end{array}$ & $\begin{array}{l}-0.383 \\
{[0.402]}\end{array}$ & $\begin{array}{l}-0.001 \\
{[0.144]}\end{array}$ & $\begin{array}{l}-0.078 \\
{[0.251]}\end{array}$ & $\begin{array}{l}0.525 \\
{[0.464}\end{array}$ & $\begin{array}{c}0.365 \\
{[0.454]}\end{array}$ & $\begin{array}{c}-0.218 \\
{[0.216]}\end{array}$ & $\begin{array}{l}-0.268 \\
{[0.227]}\end{array}$ & $\begin{array}{c}0.133 \\
{[0.648]}\end{array}$ & $\begin{array}{c}0.153 \\
{[0.639]}\end{array}$ & $\begin{array}{c}4.548 \\
{[4.848]}\end{array}$ & $\begin{array}{c}3.607 \\
{[3.883]}\end{array}$ & $\begin{array}{c}-0.238 \\
{[0.476]}\end{array}$ & $\begin{array}{c}-0.4 \\
{[0.484]}\end{array}$ \\
\hline HMO change ${ }^{\star}$ teaching & $\begin{array}{c}0.191 \\
{[0.301]}\end{array}$ & $\begin{array}{c}0.257 \\
{[0.311]}\end{array}$ & $\begin{array}{c}0.182 \\
{[0.220]}\end{array}$ & $\begin{array}{c}0.241 \\
{[0.231]}\end{array}$ & $\begin{array}{l}{[0.359} \\
{[0.473]}\end{array}$ & $\begin{array}{c}0.335 \\
{[0.468]}\end{array}$ & $\begin{array}{c}0.001 \\
{[0.189]}\end{array}$ & $\begin{array}{l}-0.026 \\
{[0.197]}\end{array}$ & $\begin{array}{c}-0.934 \\
{[0.729]}\end{array}$ & $\begin{array}{c}-0.598 \\
{[0.733]}\end{array}$ & $\begin{array}{c}1.353 \\
{[2.052]}\end{array}$ & $\begin{array}{c}1.752 \\
{[1.983]}\end{array}$ & $\begin{array}{l}-0.219 \\
{[0.371]}\end{array}$ & $\begin{array}{l}-0.358 \\
{[0.388}\end{array}$ \\
\hline HMO change ${ }^{\star}$ Gov & $\begin{array}{l}-0.098 \\
{[0.251]}\end{array}$ & $\begin{array}{l}-0.078 \\
{[0.259]}\end{array}$ & $\begin{array}{l}-0.096 \\
{[0.314]}\end{array}$ & $\begin{array}{l}-0.067 \\
{[0.318]}\end{array}$ & $\begin{array}{l}-0.974 \\
{[1.088]}\end{array}$ & $\begin{array}{c}-0.842 \\
{[1.114]}\end{array}$ & $\begin{array}{l}-0.209 \\
{[0.334]}\end{array}$ & $\begin{array}{l}-0.208 \\
{[0.340]}\end{array}$ & $\begin{array}{l}-2.027 \\
{[1.550]}\end{array}$ & $\begin{array}{l}-1.521 \\
{[1.281]}\end{array}$ & $\begin{array}{l}-2.284 \\
{[3.213]}\end{array}$ & $\begin{array}{l}-1.583 \\
{[3.300]}\end{array}$ & $\begin{array}{l}-0.105 \\
{[0.518]}\end{array}$ & $\begin{array}{l}-0.321 \\
{[0.515]}\end{array}$ \\
\hline Poor & $\begin{array}{c}-0.044 \\
{[0.086]}\end{array}$ & $\begin{array}{l}-0.057 \\
{[0.091]}\end{array}$ & $\begin{array}{l}-0.089 \\
{[0.064]}\end{array}$ & $\begin{array}{l}-0.085 \\
{[0.067]}\end{array}$ & $\begin{array}{l}-0.147 \\
{[0.112]}\end{array}$ & $\begin{array}{l}-0.147 \\
{[0.113]}\end{array}$ & $\begin{array}{l}-0.055 \\
{[0.060]}\end{array}$ & $\begin{array}{c}-0.065 \\
{[0.061]}\end{array}$ & $\begin{array}{c}-0.213 \\
{[0.158]}\end{array}$ & $\begin{array}{l}-0.221 \\
{[0.171]}\end{array}$ & $\begin{array}{l}-0.955 \\
{[1.439]}\end{array}$ & $\begin{array}{c}-0.854 \\
{[1.163]}\end{array}$ & $\begin{array}{c}-0.114 \\
{[0.116]}\end{array}$ & $\begin{array}{l}-0.128 \\
{[0.124]}\end{array}$ \\
\hline Teaching & $\begin{array}{l}-0.009 \\
{[0.100]}\end{array}$ & $\begin{array}{l}-0.012 \\
{[0.103]}\end{array}$ & $\begin{array}{l}-0.138 \\
{[0.090]}\end{array}$ & $\begin{array}{l}-0.145 \\
{[0.093]}\end{array}$ & $\begin{array}{c}0.251 \\
{[0.169]}\end{array}$ & $\begin{array}{l}0.284^{*} \\
{[0.167]}\end{array}$ & $\begin{array}{l}-0.109 \\
{[0.077]}\end{array}$ & $\begin{array}{l}-0.091 \\
{[0.080]}\end{array}$ & $\begin{array}{c}0.107 \\
{[0.368]}\end{array}$ & $\begin{array}{c}0.111 \\
{[0.382]}\end{array}$ & $\begin{array}{l}-0.030 \\
{[0.510]}\end{array}$ & $\begin{array}{c}0.183 \\
{[0.441]}\end{array}$ & $\begin{array}{c}0.120 \\
{[0.144]}\end{array}$ & $\begin{array}{l}-0.069 \\
{[0.148]}\end{array}$ \\
\hline Gov & $\begin{array}{l}-0.047 \\
{[0.063]}\end{array}$ & $\begin{array}{l}-0.056 \\
{[0.066]}\end{array}$ & $\begin{array}{l}-0.057 \\
{[0.079]}\end{array}$ & $\begin{array}{l}-0.053 \\
{[0.080]}\end{array}$ & $\begin{array}{c}0.155 \\
{[0.254]}\end{array}$ & $\begin{array}{c}0.163 \\
{[0.257]}\end{array}$ & $\begin{array}{c}0.084 \\
{[0.061]}\end{array}$ & $\begin{array}{c}0.092 \\
{[0.062]}\end{array}$ & $\begin{array}{c}-0.013 \\
{[0.198]}\end{array}$ & $\begin{array}{l}-0.023 \\
{[0.203]}\end{array}$ & $\begin{array}{c}0.291 \\
{[0.540]}\end{array}$ & $\begin{array}{c}0.292 \\
{[0.476]}\end{array}$ & $\begin{array}{l}-0.009 \\
{[0.093]}\end{array}$ & $\begin{array}{c}0.018 \\
{[0.091]}\end{array}$ \\
\hline HMO change & $\begin{array}{c}0.055 \\
{[0.209]}\end{array}$ & $\begin{array}{c}0.084 \\
{[0.216]}\end{array}$ & $\begin{array}{c}0.091 \\
{[0.154]}\end{array}$ & $\begin{array}{c}0.059 \\
{[0.161]}\end{array}$ & $\begin{array}{l}-0.327 \\
{[0.338]}\end{array}$ & $\begin{array}{l}-0.333 \\
{[0.337]}\end{array}$ & $\begin{array}{c}0.046 \\
{[0.126]}\end{array}$ & $\begin{array}{c}0.094 \\
{[0.127]}\end{array}$ & $\begin{array}{c}0.082 \\
{[0.567]}\end{array}$ & $\begin{array}{c}0.051 \\
{[0.537]}\end{array}$ & $\begin{array}{l}-1.293 \\
{[1.824]}\end{array}$ & $\begin{array}{l}-1.811 \\
{[1.800]}\end{array}$ & $\begin{array}{l}-0.229 \\
{[0.263]}\end{array}$ & $\begin{array}{l}-0.397 \\
{[0.269]}\end{array}$ \\
\hline Only hospital & $\begin{array}{l}-0.118 \\
{[0.097]}\end{array}$ & $\begin{array}{l}-0.107 \\
{[0.082]}\end{array}$ & $\begin{array}{c}0.017 \\
{[0.094]}\end{array}$ & $\begin{array}{c}0.022 \\
{[0.100]}\end{array}$ & $\begin{array}{c}0.347 \\
{[0.242]}\end{array}$ & $\begin{array}{c}0.346 \\
{[0.249]}\end{array}$ & $\begin{array}{l}0.173^{\star *} \\
{[0.059]}\end{array}$ & $\begin{array}{l}0.178^{\star *} \\
{[0.063]}\end{array}$ & $\begin{array}{c}0.272 \\
{[0.369]}\end{array}$ & $\begin{array}{c}0.066 \\
{[0.237]}\end{array}$ & $\begin{array}{l}1.328^{\star *} \\
{[0.619]}\end{array}$ & $\begin{array}{l}1.393^{\star \star} \\
{[0.563]}\end{array}$ & $\begin{array}{c}0.053 \\
{[0.117]}\end{array}$ & $\begin{array}{c}0.110 \\
{[0.124]}\end{array}$ \\
\hline Only hospital"poor & $\begin{array}{c}0.096 \\
{[0.135]}\end{array}$ & $\begin{array}{c}0.051 \\
{[0.140]}\end{array}$ & $\begin{array}{l}-0.073 \\
{[0.132]}\end{array}$ & $\begin{array}{l}-0.048 \\
{[0.139]}\end{array}$ & $\begin{array}{l}-0.158 \\
{[0.310]}\end{array}$ & $\begin{array}{l}-0.011 \\
{[0.365]}\end{array}$ & $\begin{array}{c}-0.093 \\
{[0.098]}\end{array}$ & $\begin{array}{l}-0.091 \\
{[0.104]}\end{array}$ & $\begin{array}{l}-0.409 \\
{[0.423]}\end{array}$ & $\begin{array}{l}-0.221 \\
{[0.171]}\end{array}$ & $\begin{array}{l}-0.585 \\
{[1.127]}\end{array}$ & $\begin{array}{l}-0.624 \\
{[1.001]}\end{array}$ & $\begin{array}{l}-0.011 \\
{[0.192]}\end{array}$ & $\begin{array}{l}-0.015 \\
{[0.199}\end{array}$ \\
\hline Only hospital`Teaching & $\begin{array}{c}0.220^{*} \\
{[0.132]}\end{array}$ & $\begin{array}{c}0.179 \\
{[0.137]}\end{array}$ & $\begin{array}{c}0.154 \\
{[0.115]}\end{array}$ & $\begin{array}{c}0.179 \\
{[0.122]}\end{array}$ & $\begin{array}{l}-0.251 \\
{[0.266]}\end{array}$ & $\begin{array}{l}-0.258 \\
{[0.270]}\end{array}$ & $\begin{array}{c}0.035 \\
{[0.080]}\end{array}$ & $\begin{array}{c}0.024 \\
{[0.085]}\end{array}$ & $\begin{array}{l}-0.282 \\
{[0.491]}\end{array}$ & $\begin{array}{c}0.111 \\
{[0.382]}\end{array}$ & $\begin{array}{l}-1.533^{* \star} \\
{[0.644]}\end{array}$ & $\begin{array}{l}-1.659^{* *} \\
{[0.618]}\end{array}$ & $\begin{array}{c}0.118 \\
{[0.169]}\end{array}$ & $\begin{array}{c}0.074 \\
{[0.176]}\end{array}$ \\
\hline Only hospital ${ }^{*}$ gov & $\begin{array}{l}0.303^{* *} \\
{[0.123]}\end{array}$ & $\begin{array}{c}0.287 \\
{[0.130]}\end{array}$ & $\begin{array}{c}0.110 \\
{[0.135]}\end{array}$ & $\begin{array}{l}0.095 \\
{[0.139]}\end{array}$ & $\begin{array}{l}-0.206 \\
{[0.460]}\end{array}$ & $\begin{array}{l}-0.213 \\
{[0.464]}\end{array}$ & $\begin{array}{l}-0.208 \\
{[0.298]}\end{array}$ & $\begin{array}{l}-0.199 \\
{[0.185]}\end{array}$ & $\begin{array}{c}0.674 \\
{[0.481]}\end{array}$ & $\begin{array}{l}-0.022 \\
{[0.203]}\end{array}$ & $\begin{array}{c}0.307 \\
{[1.022]}\end{array}$ & $\begin{array}{l}-0.334 \\
{[0.889]}\end{array}$ & $\begin{array}{c}0.125 \\
{[0.182]}\end{array}$ & $\begin{array}{r}0.119 \\
{[0.189]}\end{array}$ \\
\hline $\begin{array}{l}\text { Demographic Characteristics } \\
\text { Hospital Characteristics }\end{array}$ & $\begin{array}{l}\text { yes } \\
\text { yes }\end{array}$ & $\begin{array}{l}\text { yes } \\
\text { yes }\end{array}$ & $\begin{array}{l}\text { yes } \\
\text { yes }\end{array}$ & $\begin{array}{l}\text { yes } \\
\text { yes }\end{array}$ & $\begin{array}{l}\text { yes } \\
\text { yes }\end{array}$ & $\begin{array}{l}\text { yes } \\
\text { yes }\end{array}$ & $\begin{array}{l}\text { yes } \\
\text { yes }\end{array}$ & $\begin{array}{l}\text { yes } \\
\text { yes }\end{array}$ & $\begin{array}{l}\text { yes } \\
\text { yes }\end{array}$ & $\begin{array}{l}\text { yes } \\
\text { yes }\end{array}$ & $\begin{array}{l}\text { yes } \\
\text { yes }\end{array}$ & $\begin{array}{l}\text { yes } \\
\text { yes }\end{array}$ & $\begin{array}{l}\text { yes } \\
\text { yes }\end{array}$ & $\begin{array}{l}\text { yes } \\
\text { yes }\end{array}$ \\
\hline $\begin{array}{l}\text { Market characteristics } \\
\mathrm{N}\end{array}$ & 894 & 894 & 894 & 894 & 894 & 894 & 894 & 894 & 894 & 894 & 894 & 894 & 894 & 894 \\
\hline R2 & 0.163 & 0.292 & 0.240 & 0.252 & 0.269 & 0.352 & 0.183 & 0.220 & 0.204 & 0.194 & 0.211 & 0.225 & 0.258 & 0.273 \\
\hline
\end{tabular}

Robust standard errors appear in brackets. All regressions include 51 state dummy variables and 7 MSA size dummy variables.

* Statistically significantly different from zero at the 10 percent level.

** Statistically significantly different from zero at the 5 percent level. 